Eur. J. Clin. Chem. Clin. Biochem.

Vol. 32, 1994, pp. 53-55

(c) 1994 Walter de Gruyter \& Co.

Berlin $\cdot$ New York

\title{
Biological Half-Life of Prostate-Specific Antigen after Radical Prostatectomy
}

\author{
By J. P. van Straalen ', M. M. F. Bossens ${ }^{2}$, T. M. de Reijke ${ }^{2}$ and G. T. B. Sanders ${ }^{1}$ \\ ${ }^{1}$ Department of Clinical Chemistry, Academical Medical Centre, Amsterdam, The Netherlands \\ 2 Department of Urology, Academical Medical Centre, Amsterdam, The Netherlands
}

(Received July 12/October 15, 1993)

Summary: The disappearance pattern of prostate-specific antigen from serum after a standard radical prostatectomy was studied in eight patients with cancer confined to the prostate. The results were used to plot an elimination curve and calculate the best fit. A biphasic pattern was found with an average biological half-life of 1.63 hours in the $\alpha$-phase, and 4.63 days in the $\beta$-phase. Based on these results it is concluded that determination of prostatespecific antigen concentrations less than one month after a standard radical prostato-vesiculectomy has no value for the detection or exclusion of residual malignant processes.

\section{Introduction}

In 1971, a gamma seminoprotein was detected (1) in seminal plasma, and subsequently isolated and characterized by $L i(2)$ and Sensabaugh (3). In 1979 Wang (4) purified this protein from natural prostate tissue and named it prostate-specific antigen. After the introduction of commercial kits for the determination of prostatespecific antigen, prostatic acid phosphatase was replaced by prostate-specific antigen as a tumour marker for prostate cancer $(5,6)$. After radical prostatectomy as a treatment for localized cancer, the absence of residual tumour $\left(\mathrm{pT}_{2-3} \mathrm{~N}_{0} \mathrm{M}_{0}\right)$ is indicated by a decrease of serum prostate-specific antigen until it is undetectable by the current generation of immunoassays for prostate-specific antigen (6). In view of differences in the observed biological washout patterns and disappearance time of prostate-specific antigen after a standard radical prostatectomy, we initiated the present study to determine the biological half-life of prostate-specific antigen.

\section{Methods and Patients}

Prostate-specific antigen was measured by a solid-phase two-site immunoenzymatic assay employing two monoclonal antibodies. We used a commercial kit, Tandem R-E, from Hybritech (Hybri- tech Inc, San Diego CA, USA), according to the instructions of the manufacturer. The colorimetric measurements were performed on a Photon II spectrophotometer.

Prostate-specific antigen excretion patterns were followed in eight patients ranging from 59 to 75 years, suffering from prostatic cancer. The prostates were removed surgically, together with the seminal vesicles. In all eight patients the cancer was confined to the prostate; the bone scan was negative, and there was no lymph node involvement at lymphadenectomy $\left(\mathrm{pT}_{2-3} \mathrm{~N}_{0} \mathrm{M}_{0}\right)$. The final pathological stage and grade was $\mathrm{pT}_{2} \mathrm{G}_{2}(\mathrm{n}=2), \mathrm{pT}_{3} \mathrm{G}_{2}(\mathrm{n}=4)$ and $\mathrm{pT}_{3} \mathrm{G}_{3}(n=2)$, respectively. During follow-up the prostate-specific antigen concentration remained for at least one year after surgical intervention within the female range; during this time there was no evidence of clinical recurrence, based on digital rectal examination, trans rectal ultra sonography of the prostate, bone-scan and chest $\mathrm{X}$-ray. Venous blood was collected according to the following scheme: before the intervention two samples were taken at 9 a. m. with a time interval of one day. The actual moment of removal of the prostate was called $T_{0}$. During and after the intervention, blood was collected every hour until two hours after $T_{0}$, followed by collection at $3,6,9$ and 12 hours after $T_{0}$. During the following ten days one blood sample was taken each day, always at 9 a.m. Until analysis all the serum samples were stored at $-20^{\circ} \mathrm{C}$. Prostate-specific antigen was determined when all the samples from one patient were available.

For the statistical evaluation of the data we used a computer program called PCNONLIN NONLINEAR ESTIMATION from Statistical Consulting Inc (Lexington, Kentucky, USA), which is able to choose the right form of elimination through best fit of the elimination curves of the individual patients (one, two or three compartment model). 


\section{Results and Discussion}

During the surgical extirpation of the prostate, prostatespecific antigen concentrations were increased to between three and ten times their starting levels. It was noted that a biphasic disappearance curve resulted after total removal of the prostate. The mean biological halflife in the first phase ( $\alpha$-phase) was 1.63 hours (SD 0.69 ). After the first twenty-four hours the prostatespecific antigen disappearance was more gradual. In this phase ( $\beta$-phase) the biological half-life was 4.63 days (SD 2.26). The graphic fit of the disappearance is shown in figure 1 and the separate data of the individual patients are shown in table 1.

The correctness of fit is very high (0.997). Data are expressed as percentage of $T_{0}$ values. In the literature several other studies have been reported but they show no general agreement as to the disappearance rate. Our observations contradict those of Oesterling et al. (7), who found a single phase elimination with a half-life of 3.15 days (SD 0.09) determined with a log-linear regression model. They stated that prostate-specific antigen concentrations were undetectable after 5 to 6 times the biological half-life, meaning that 16 days after the radical prostatectomy the prostate-specific antigen concentrations were in the female range. Stamey et al. (6) found a two-phase elimination: an $\alpha$-phase of 12.6 hours (SD 19.7) and a $\beta$-phase of 2.2 days (SD 0.8). Their data were calculated from the natural log of the prostatespecific antigen concentration plotted against time. These data fitted a two compartment model of first order elimination kinetics. They also claimed that prostatespecific antigen concentrations were no longer detectable after fourteen days. The fast decline in the first phase, as seen in our results, is probably based on com-
Tab. 1 Disappearance rates, expressed as $t_{1 / 2}$ of prostate-specific antigen in the 8 individual patients.

\begin{tabular}{llr}
\hline Patient & $\begin{array}{l}\alpha-P h a s e \\
\mathrm{t}_{1 / 2}(\mathrm{~h})\end{array}$ & $\begin{array}{l}\beta \text {-Phase } \\
\mathrm{t}_{1 / 2}(\mathrm{~h})\end{array}$ \\
\hline 1 & 1.030 & 112.1 \\
2 & $0.850 \quad, \quad$ & 182.5 \\
3 & 2.907 & 43.9 \\
4 & 2.188 & 70.6 \\
5 & 1.954 & 77.4 \\
6 & 1.325 & 90.8 \\
7 & 0.858 & 98.8 \\
8 & 1.960 & 213.7 \\
Mean & 1.634 & 111.2 \\
Standard deviation & 0.690 & 54.2 \\
\hline
\end{tabular}

plex formation between liberated prostate-specific antigen and mainly $\alpha_{1}$-antichymotrypsin (10), and possibly other acute phase proteins such as $\alpha_{2}$-macroglobulin. Examples of these complexes are described by Christensson (11).

There is some doubt as to whether the Tandem-E prostate-specific antigen test method determines these complexes. $\alpha_{2}$-Macroglobulin is known to encapsulate the target protein at complex formation (11). This happens in such a way that no antiserum will detect prostatespecific antigen bound to this acute phase protein. But since the concentration of these complexes is low (12) it is not to be expected that their presence will influence our results to a great extent. The performance characteristics of the Tandem-E prostate-specific antigen assay are similar to those of the Tandem- $R$ assay (13), and it has been reported (10) that the latter kit also detects prostate-specific antigen complexed to $\alpha_{1}$ =antichymotrypsin. Therefore, it may be concluded that the Hybri-

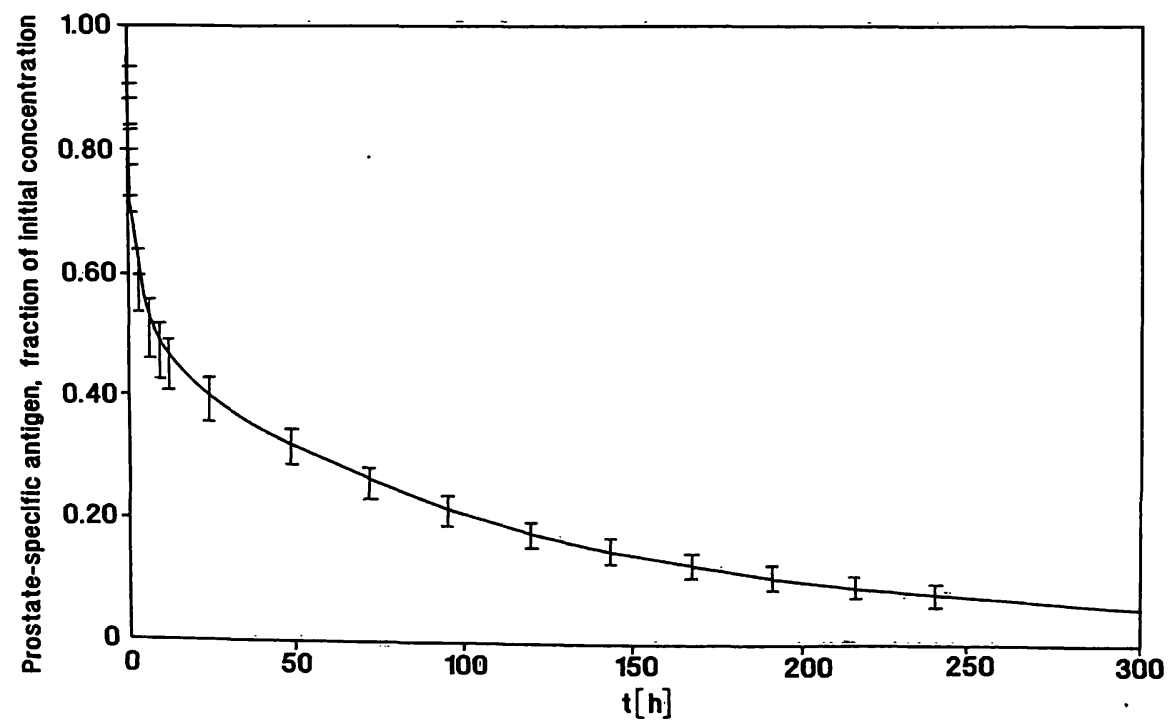

Fig. 1 Typical disappearance curve of prostate-specific antigen concentrations from serum after prostatectomy, expressed as frac-

tion of initial concentration versus time. Values given are means \pm 1 SD $(n=8)$. 
tech Tandem-E, as used by us, measures free prostatespecific antigen, as well as prostate-specific antigen bound to $\alpha_{1}$-antichymotrypsin. In the second phase the slow decrease of prostate-specific antigen might be due to a slow release of prostate-specific antigen from the complexes and/or their gradual disappearance from plasma. This issue will require further study.

\section{Conclusion}

In conclusion it can be stated that prostate-specific antigen disappears after radical prostatectomy in accordance with a biphasic excretion model, consisting of an $\alpha$ -

\section{References}

1. Hara, M., Koyanagi, Y., Inoue, T. \& Fukuyama, T. (1971) Some physicochemical characteristics of gamma-semenprotein, an antigenic component specific for human seminal plasma. Jpn. J. Legal Med. 25 322-324.

2. Li, T. S. \& Beling, C. G. (1973) Isolation and characterization of two specific antigens of human seminal plasma. Fertil. Steril. 24, 134-144.

3. Sensabaugh, G. F. (1978) Isolation and characterization of a semen-specific protein from seminal plasma: A potential new marker for semen identification. J. Forensic Sci. 23, 106-115.

4. Wang, M. C., Valenzuela, L. A., Murphy, G. P. \& Chu, T. M. (1979) Purification of a human prostate specific antigen. Invest. Urol. 17, 159-163.

5. Killian, C. S., Emrich, L. J. \& Vargas, F. P. (1986) Relative reliability of five serially measured markers for prognosis of progression in prostate cancer. J. Natl. Cancer Inst. 76, 176185.

6. Stamey, T. A., Yang, N., Hay, A. R., McNeal, J. E., Freiha, F. S. \& Redwine, E. (1987) Prostate-specific antigen as a serum marker for adenocarcinoma of the prostate. N. Eng. J. Med. 317, 909-916.

7. Oesterling, J. E., Chan, D. W, Epstein, J. I., Kimball, A. W., Bruzek, D. J., Rock, R. C., Brendler, C. B. \& Walsh, P. C. (1988) Prostate specific antigen in the preoperative and postoperative evaluation of localized prostatic cancer treated with radical prostatectomy. J. Urology 139, 766-772.

8. Mannini, D., Maver, P., Aiello, E., Corrado, G., Vecchi, F., Bellanova, B. \& Marengo, M. (1988) Spontaneous circadian phase with a half-life of 1.63 hours and a $\beta$-phase with a half-life of 4.63 days.

Based on our results and the assumption that 6 times the half-life should elapse before a steady level has been reached, we advise that determination of prostatespecific antigen levels less than one month after a standard radical prostato-vesiculectomy has no value for the detection or exclusion of residual malignant processes.

\section{Acknowledgement}

We wish to express our thanks to the department of Clinical Pharmacology (head: Prof. dr. C. J. van Boxlel) for the statistical processing of the data. fluctuations of prostate specific antigen and prostatic acid phosphatase serum activities in patients with prostatic cancer. Urol. Res. 16, 9-12.

9. Chan, D. W. 81988) PSA as a marker for prostatic cancer. Lab. Management 26, 135-139.

10. Lilja, H., Christensson, A., Dahlén, U., Matikainen, M. T., Nilsson, O., Pettersson, K. \& Lövgren, T. (1991) Prostatespecific antigen in serum occurs predominantly in complex with $\alpha_{1}$-antichymotrypsin. Clin. Chem. 37, 1618-1625.

11. Christensson, A., Laurell, C. B. \& Lilja, H. (1990) Enzymatic activity of prostate-specific antigen and its reaction with extracellular serine proteinase inhibitors. Eur. J. Biochem. 194, $755-763$.

12. Stenman, U-H., Leinonen, J., Alfthan, H., Rannikko, S., Tuhkanen, K. \& Alfthan, O. (1991) A complex between prostate-specific antigen and $\alpha_{1}$-antichymotrypsin is the major form of prostate-specific antigen in serum of patients with prostatic cancer: Assay of the complex improves clinical sensitivity for cancer. Cancer Res. 51, 222-226.

13. Oesterling, J. E. (1991) Prostate specific antigen: A critical assessment of the most useful tumor marker for adenocarcinoma of the prostate. J. Urology 145, 907-923.
Jan P. van Straalen
Academic Medical Centre
Meibergdreef 9
NL-1105 AZ Amsterdam
The Netherlands 
